\title{
A novel approach for manual de-torsion of an atypical (outward) testicular torsion with bedside Doppler ultrasonography guidance
}

\author{
Mustafa Güneş, MD; $;^{*}$ Mehmet Umul, MD; ${ }^{*}$ Ahmet Orhan Çelik, MD;: Hamit Hakan Armağan, MD;* \\ Bumin Değirmenci, $M D^{ \pm}$
}

*Department of Urology, Faculty of Medicine, Süleyman Demirel University, Isparta, Turkey; ${ }^{ \pm}$Department of Radiology, Faculty of Medicine, Süleyman Demirel University, Isparta, Turkey; ${ }^{*}$ Department of Emergency Medicine, Faculty of Medicine, Süleyman Demirel University, Isparta, Turkey

Cite as: Can Urol Assoc J 2015;9(9-10):E676-8. http://dx.doi.org/10.5489/cuaj.2849 Published online September 9, 2015.

\section{Abstract}

A 17-year-old boy presented with right testicular torsion to the lateral side. Torsion was diagnosed by physical examination; the colour Doppler ultrasonography (CDU) confirmed right testicular torsion with minimal peripheral hydrocele. Transverse and longitudinal examination of the spermatic cord with ultrasound and CDU revealed a counter-clockwise testicular torsion. Manual de-torsion was performed in a clockwise direction (7200) and testicular blood flow and the neutral position of the spermatic cord were confirmed by CDU. We did not encounter a residual twist of the spermatic cord upon surgical exploration. In our experience, ultrasound and CDU may predict the direction of testicular torsion and may allow appropriate management of cases prior to surgery.

\section{Introduction}

Testicular torsion is an important and relatively common urologic emergency that often requires surgical intervention to provide testicular viability. ${ }^{1}$ Manual de-torsion is a critical manoeuvre that protects the testicular viability in patients when there is a surgical delay and it also provides significant pain relief. A variety of successful applications have been reported. ${ }^{2,3}$ Manual de-torsion is a non-invasive method that can be performed at the bedside with the guidance of colour Doppler ultrasonography (CDU). Although the main approach for manual de-torsion is to de-rotate the testis and the spermatic cord laterally, almost one-third of patients may require medial de-torsion. ${ }^{4}$ Therefore, dramatic pain relief and a reduction of the rotation resistance in the course of manual de-torsion should be considered. ${ }^{2,3}$ Monitoring the testicular arterial blood flow with CDU following manual de-torsion is also crucial. ${ }^{2,3}$

To our knowledge, there is no sufficient data about the prediction of the direction of testicular torsion. We present a case of atypical (outward) testicular torsion demonstrated by $\mathrm{CDU}$ and the simultaneous manual de-torsion of the spermatic cord.

\section{Case report}

A 17-year-old boy was admitted to our clinic with sudden onset right testicular pain that had been ongoing for 4 hours. He had undergone harelip repair during childhood. Remarkably, his medical history also revealed intermittent right testicular torsion. Physical examination revealed right hemi-scrotal swelling, tenderness, and a high-riding right testicle. Cremasteric reflex was absent. A bedside B-mode ultrasound and $C D U$ were performed by a radiologist using an L14-5 MHz linear array transducer (Xario 200; Toshiba, Tokyo, Japan). The normal left testicle was examined first to optimize the colour settings. The right testis was slightly larger than the left, measuring $4.1 \times 2.9 \times 2.3 \mathrm{~cm}$. Minimally decreased echogenicity was noted diffusely, which was surrounded by a minimal hydrocele (Fig. 1, part A). No blood flow could be identified within this testis by colour and power Doppler examination (Fig. 1, part B). Transverse viewing of the spermatic cord with $\mathrm{CDU}$ showed a counter-clockwise testicular torsion (Fig. 1, part C, Fig. 1, part D, Video 1 (http:// bit.ly/1 K5M7bC). Based on the CDU findings we immediately performed manual de-torsion with a $720^{\circ}$ inward motion without local/systemic anesthesia (Fig. 2, part A). The patient's pain was relieved immediately after de-torsion, indicating that the manoeuvre had been effective. Furthermore, colour and pulsed Doppler ultrasound examination of the right testis revealed normal arterial flow following manual de-torsion and the spermatic cord was observed in the neutral plane in the cranio-caudal view (Fig. 2, part C, Fig. 2, part D). Within 1 hour, the patient underwent bilateral orchiopexy. The right spermatic cord had no a residual twist that required further de-torsion during surgery. The testicle was viable (Fig. 2, part B) and the patient was discharged later that day. 


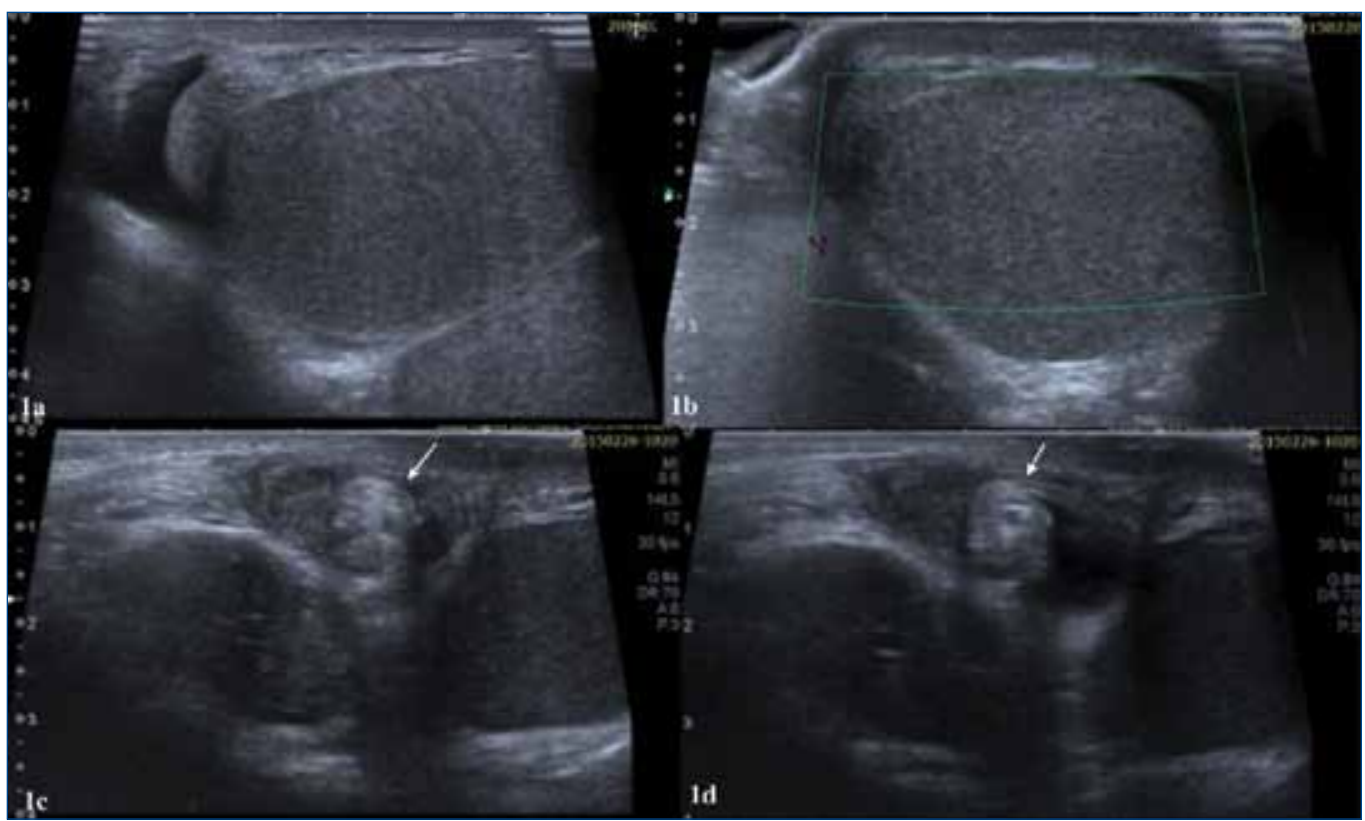

Fig. 1. Scrotal ultrasonography reveals a moderate hydrocele surrounding the testis and edematous testis (A) The longitudinal image of the torsive right testis shows no blood flow by color Doppler examination (B) Sonographic image shows a markedly edematous spermatic cord and cranio-caudal examination reveals a counter-clockwise twist; the white arrow shows the direction of the torsion $(\mathrm{C}, \mathrm{D})$.

\section{Discussion}

Manual de-torsion of the spermatic cord may provide sudden pain relief and it may be substantial for testicular viability. Concordance with CDU findings may increase treatment success. False-positive and false-negative diagnosis rates for testicular torsion have decreased with the introduction of CDU. ${ }^{5}$ Doppler sonography in testicular torsion diagnosis has become the initial imaging study of choice because of its reported high sensitivity $(78.6 \%-89 \%)$ and specificity $(77 \%-100 \%) .{ }^{6}$ Sudden relief of pain is an important indicator for success. ${ }^{2,3}$ However, manual de-torsion of the testes under intravenous anesthesia (diprivan) or spermatic cord block has been reported. ${ }^{7}$ Local/systemic anesthesia may prevent optimal non-surgical management of testicular torsion in relation to pain relief in atypical (outward) cases. ${ }^{8}$ Thus, we prefer manual de-torsion without anesthesia, as seen in our present case. Determining the exact direction of the torsion prior to manual de-torsion may eliminate inappropriate interventions. Therefore, we prefer to examine the spermatic cord with CDU and B-mode ultrasound before manual de-torsion. In the present case, CDU and ultrasound examination of the longitudinal axis and transverse plane revealed a counter-clockwise twist of the spermatic cord. Therefore, we planned to perform an inward de-torsion contrary to the recommendations from the initial intervention. ${ }^{2-4}$ Sudden relief of pain occurred and the testicular arterial flow was demonstrated by CDU after the $720^{\circ}$ inward detorsion was completed. In addition, after the manoeuvre, the spermatic cord was in the neutral position. Furthermore, exact de-torsion of the cord was confirmed during scrotal exploration.

The lack of sufficient data to predetermine the direction of testicular torsion might be a consequence of common practical approaches. Based on our observations, manual de-torsion is not widely performed. Owing to the risk of recurrence and the possibility of ineffective manual de-torsion, surgical orchiopexy is indicated in patients following manual de-torsion, and this situation may be reason for the rare application of manual de-torsion. However manual detorsion may be substantial for testicular viability especially in patients in which there is a delay in getting to the operating room. To obtain an effective result, atypical (outward) testicular torsion should be considered.

\section{Conclusion}

Manual de-torsion could be an effective treatment for testicular torsion. However, the possibility of atypical (outward) testicular torsion should be always kept in mind. Thus, as a novel approach is the routine use of CDU prior to manual de-torsion of the spermatic cord to identify the exact direction of the testicular torsion. Clinical symptoms and radiological findings should be evaluated together for optimal management. Furthermore, regarding the risk for recurrent testicular torsion, successful manual de-torsion of the spermatic cord should always be followed by surgical orchiopexy. 
Moorthy et al.

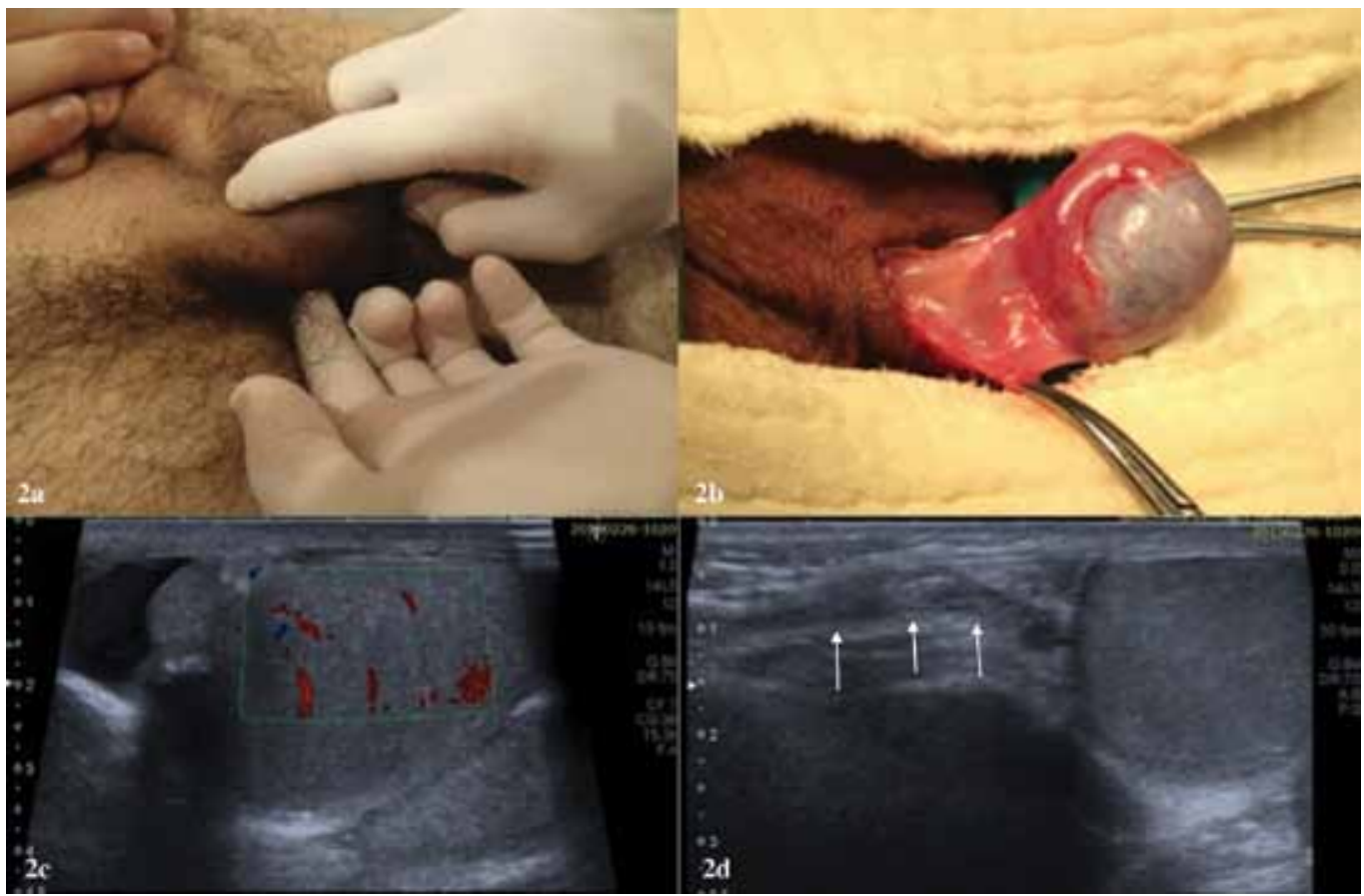

Fig. 2. Clockwise $720^{\circ}$ manual de-torsion. (A) Perioperative view of the spermatic cord without residual torsion, edema, and congestion. (B) Spectral analysis of the central artery by CDU following manual de-torsion shows the immediate occurrence of central perfusion. (C) White arrows indicate the spermatic cord in the neutral plane in the cranio-caudal view (D).

Video 1. Ultrasonographic evaluation reveals counter-clockwise twisting before manual de-torsion; the green arrows show the direction of the spermatic cord torsion (http://bit.ly/1K5M7bC).

Competing interests: The authors all declare no competing financial or personal interests.

This paper has been peer-reviewed.

\section{References}

1. Gürocak S, Yilmaz A, Alp E, et al. Inflammation and oxidative stress in testicular torsion: Do they deserve intensive treatment to save both guilty and innocent testes? Urology 2011;78:164-9. http://dx.doi. org/10.1016/j.urology.2010.12.069
2. Cornel EB, Karthaus HF. Manual detorsion of the twisted spermatic cord. BJU Int 1999;83:672-4. http:// dx.doi.org/10.1046/i.1464-410x.1999.00003.x

3. Garel L, Dubois J, Azzie G, et al. Preoperative manual detorsion of the spermatic cord with Doppler ultrasound monitoring in patients with intravaginal acute testicular torsion. Pediatr Radiol 2000;30:41-4. http://dx.doi.org/10.1007/s002470050012

4. Sessions AE, Rabinowitz R, Hulbert WC, et al. Testicular torsion: Direction, degree, duration and disinformation. J Urol 2003;169:663-5. http://dx.doi.org/10.1016/S0022-5347(05)63987-0

5. Agrawal AM, Tripathi PS, Shankhwar A, et al. Role of ultrasound with color Doppler in acute scrotum management. J Family Med Prim Care 2014;3:409-12.

6. Nussbaum Blask AR, Rushton HG. Sonographic appearance of the epididymis in pediatric testicular torsion. AJR Am J Roentgenol 2006; 187:1627-35. http://dx.doi.org/10.2214/AJR.05.0461

7. Harvey M, Chanwai G, Cave G. Manual testicular detorsion under propofol sedation. Case Rep Med 2009;2009:529346. htrp://dx.doi.org/10.1155/2009/529346

8. Güneş $M$, Umul $M$, Altok $M$. Atypical testicular torsion: We must be cautious in the course of manual detorsion. Pediatr Emerg Care 2015; http://dx.doi.org/10.1097/pec.0000000000000437

Correspondence: Dr. Mustafa Güneş, Department of Urology, Faculty of Medicine, SDU Research Hospital East Campus, 32260 Çünür, Isparta, Turkey; mustafagunes@sdu.edu.tr 